\title{
RESONANCES IN AN EVOLVING HOLE IN THE SWASH
}

\section{ZONE}

\author{
Steve Elgar ${ }^{1}$, Britt Raubenheimer ${ }^{2}$, Jim Thomson ${ }^{3}$, and Melissa Moulton ${ }^{4}$
}

1 Woods Hole Oceanographic Institution, MS11, Woods Hole, MA 02543, elgar@whoi.edu.

2 Woods Hole Oceanographic Institution, MS12, Woods Hole, MA 02543, britt@whoi.edu.

3 University of Washington Applied Physics Laboratory, Seattle, WA 98105, jthomson@apl.washington.edu,

4 Woods Hole Oceanographic Institution, MS12, Woods Hole, MA 02543, melissarmoulton@gmail.com.

\section{ABSTRACT:}

Water oscillations observed in a 10-m diameter, 2-m deep hole excavated on the foreshore just above the low-tide line on an ocean beach are consistent with theory. When swashes first filled the initially circular hole on the rising tide, the dominant mode observed in the crossshore velocity was consistent with a zero-order Bessel function solution (sloshing back and forth). As the tide rose and swash transported sediment, the hole diameter decreased, the water depth inside the hole remained approximately constant, and the frequency of the sloshing mode increased according to theory. About an hour after the swashes first reached the hole, it had evolved from a closed circle to a semi-circle, open to the ocean. When the hole was nearly semi-circular, the observed cross-shore velocity had two spectral peaks, one associated with the sloshing of a closed circle, the other associated with a quarter-wavelength mode in an open semi-circle, both consistent with theory. As the hole evolved further toward a fully semi-circular shape, the circular sloshing mode decreased, while the quarterwavelength mode became dominant. 


\section{Introduction}

Enclosed and semi-enclosed bodies of water resonate at the frequencies of their natural modes. The resonant frequencies depend on the basin geometry (Strutt 1877, Lamb 1916, Rabinovich 2009, and references therein), and have been investigated in estuaries, harbors, inlets, fjords, and bays (Wiegel 1964, Raichlen 1966, Miles 1974, Raichlen and Lee 1992, Okihiro and Guza 1993, references therein, and many others). The response of harbors to a range of forcing frequencies, and the change in resonance owing to different entrance channel configurations has been investigated theoretically (Miles and Munk 1966, Unluata and Mei 1975, Wu and Liu 1990, and many others). Small, man-made structures designed to resonate at specific frequencies also have been investigated theoretically (Valembois 1953, Lates 1963, James 1970a), as well as with laboratory experiments (Valembois 1953, James 1970b, 1970c, 1971a, 1971b). Resonators have been constructed along entrance channels to protect harbors from seiches driven by waves from the open ocean. Field studies of these structures have focused on the sediment transported by the currents associated with the resonant mode (Donnely and Macinnis 1968, and Prandle 1974). However, there have been few, if any, field observations of resonances in small man-made structures forced by broadband ocean wind waves. Here, it is shown that as the shape of a hole excavated near the low-tide line on an ocean beach evolves from a closed circle to a semi-circle open to the ocean, the water oscillates at the theoretically predicted natural modes of the system.

\section{Field Observations}

A 10-m diameter, 2-m deep circular hole (Figures 1a and 2a) was excavated with a backhoe slightly above the low-tide line on a relatively long, straight Atlantic Ocean beach on the Outer Banks of North Carolina, near Duck. About an hour after the excavation was completed 
the tide had risen sufficiently for swash running up the beach to reach the sides of the hole and fill it with water (Figure 1a). As the tide rose further, more swash reached the hole, which developed a small gap on the seaward edge (Figure 1b). As the swash transported sediment, the hole filled primarily from the sides, its wetted diameter decreased (Figure 2c), the gap enlarged (Figure 1c), and the closed circle evolved toward an open semi-circle (Figures 1d and 2b). The water depth inside the hole remained approximately constant (Figure 2c) because the tide was rising as the hole filled with sediment. About 2 hours after the swash first reached the hole, it was refilled with sediment, and the bathymetry of the hole location and the surrounding beach was similar to the bathymetry observed before the excavation.

The hole and surrounding beach were surveyed continually with GPS carried by walkers (horizontal accuracy of +/- $0.10 \mathrm{~m}$, vertical accuracy of +/- $0.03 \mathrm{~m}$ ), and every 12 minutes sand levels at the 7 sensor locations in the hole (Figures 1 and 2a) were measured by hand (accuracy +/- $0.02 \mathrm{~m}$ ), and the instruments were raised to prevent burial as the hole filled. The initial volume of the excavated hole was approximately $157 \mathrm{~m}^{3}$. The removed sand was stored above the high-tide line, where it remained during the experiment. Beach surveys did not indicate changes in sediment levels alongshore of the excavation site, suggesting the sediment that refilled the hole was transported primarily from offshore. The hole refilled with sand in less than 2 hrs, implying a total infilling rate of approximately $0.02 \mathrm{~m}^{3} / \mathrm{s}$ and a transport rate across the 10 -m diameter of roughly $0.002 \mathrm{~m}^{3} / \mathrm{s}$ per $\mathrm{m}$. Consistent with previous swash zone studies (Watts 1953, Beach and Sternberg 1991), these sediment transport rates are an order of magnitude greater than those observed in the inner and outer surf zones during strong storms on this beach (Thornton et al. 1996, Gallagher et al. 1998). 
An array of pressure gages in $8 \mathrm{~m}$ depth, $800 \mathrm{~m}$ offshore of the shoreline was used to estimate incident waves. Seven acoustic Doppler current meters were deployed in the hole (Figures 1 and 2) and three additional current meters with colocated pressure sensors (not shown) were deployed at locations extending from the hole to a $0.8-\mathrm{m}$ high sandbar in 1.2-m water depth. Incident significant wave heights in $8 \mathrm{~m}$ depth were about $0.4 \mathrm{~m}$, with most of the energy in a narrow swell peak with frequency $f=0.1 \mathrm{~Hz}$, and approached the beach about $28^{\circ}$ from normal incidence. Incident waves did not change significantly during the 2-hr time period studied here. Refraction and shoaling resulted in the 0.4 to $0.5 \mathrm{~m}$ high waves propagating within $5^{\circ}$ of normal incidence that were observed in $1.2 \mathrm{~m}$ depth, $80 \mathrm{~m}$ offshore of the hole. Cross- and alongshore currents were less than $0.15 \mathrm{~m} / \mathrm{s}$ in $1.2 \mathrm{~m}$ depth, and less than $0.10 \mathrm{~m} / \mathrm{s}$ in the hole, except when the hole had evolved to a semi-circle at which time cross-shore currents near the seaward edge increased to $0.50 \mathrm{~m} / \mathrm{s}$. Visual observations (green water in Figure 1 is dye) suggest the strong offshore-directed cross-shore flows near the open edge of the semi-circle at least partially were owing to a circulation pattern similar to that observed in beach cusps (Lane 1888, Evans 1938, 1945, Bowen and Inman 1971, Guza and Inman 1975), with the swash running up the beach on both sides of the hole being directed into the hole, and out along the center (Figure 1d shows strong seaward directed outflow).

Energy density spectra from 512-s long time series of cross-shore velocity observed in the hole have peaks that do not always coincide with the frequency of the incident wind waves (Figure 3). Specifically, although between 17:00 and 19:00 hrs the incident waves (observed in $1.2 \mathrm{~m}$ depth, $80 \mathrm{~m}$ offshore of the hole) were dominated by $f=0.10 \mathrm{~Hz}$ swell (black curve, 
Figure 3), the motions inside the hole had spectral peaks that ranged from near $f=0.14 \mathrm{~Hz}$ (red curve, Figure 3) when water first entered the hole (17:00 hrs, Figure 1a) to $f=0.16 \mathrm{~Hz}$ (green curve, Figure 3) to $f=0.18 \mathrm{~Hz}$ (blue curve, Figure 3), to $f=0.10$ (pink curve, Figure 3 ) as the

hole evolved (Figure 1). Although the confidence limits on spectral estimates with 20 degrees of freedom (obtained by merging 10 neighboring frequencies in periodogram estimates of the spectra, resulting in a frequency resolution of approximately $0.02 \mathrm{~Hz}$ ) are large (90\% bars in Figure 3), the peaks are statistically significant. Alongshore velocities have spectral peaks at frequencies similar to those for cross-shore velocities, as well as at other frequencies, but alongshore velocities were about an order of magnitude smaller than cross-shore velocities, resulting in less confidence in spectral estimates, and thus are not considered further.

\section{Theory}

The water surface in a circular basin has many resonant modes (Lamb 1916), similar to acoustic resonators (Strutt 1877). The lowest mode is when the water sloshes back and forth from one side of the circle to the other (i.e., a half-wavelength mode). The frequency of this mode is given by (Lamb [Art 191], 1916):

$$
f=\frac{\sqrt{g h}}{3.4 r}
$$

where $g$ is gravitational acceleration, $h$ is the water depth, $r$ is the radius of the circle, and the constant 3.4 comes from the roots of the first-order asymmetrical Bessel function solutions for a sloshing mode. Changes in surface elevation are minimum (node) and horizontal velocities are maximum (anti-node) along an alongshore line through the center of the hole (i.e., the sloshing is in the cross-shore direction). 
Unlike closed basins, for which the lowest mode corresponds to a half wavelength, the lowest mode in a basin open to the ocean is a quarter-wavelength resonance (Korgen 1995) for which there is an anti-node in surface elevation (node in cross-shore velocity) at the closed edge, and a node in surface elevation (anti-node in cross-shore velocity) at the open boundary. The frequency of the quarter-wavelength resonator in a semi-circular basin open to the ocean is given by (Wilson 1972, Rabinovich 2009):

$$
f=\frac{\sqrt{g h}}{4.44 L}
$$

where $\mathrm{L}$ is the radius (distance from open boundary to farthest point of the semi-circle) and the constant 4.44 comes from an approximate zero of the lowest-order Bessel function solution for a semi-circular basin. If the open basin is rectangular, the constant is 4.0.

\section{Results}

The observed spectral peaks in cross-shore velocity are consistent with theoretical predictions (Figure 4). When the hole was a closed circle (Figures 1a and 2a), the water surface oscillated at the predicted (Eq. 1) frequency ( $f=0.14 \mathrm{~Hz}$ ) of the lowest mode (sloshing) for the observed geometry and water depth (Figure 2c), forced by occasional swash overwashing the sides

(Figure 4, where the upper solid curve is the predicted frequency for the lowest-order resonant mode for a closed circle given the observed changing diameter and water depth). The phase relationships between spatially separated (sensors in Figures 1 and 2) observations of crossshore velocity at the resonant peak are consistent with a lowest-order mode, with water sloshing back and forth in the cross-shore direction. As the tide rose and sediment was transported by swash, the diameter of the wetted circle decreased (Figure 2c), the water depth 
inside the hole changed only slightly (Figure 2c), and the observed and predicted resonant frequencies increased (Figures 3 and 4, Time $=17: 00$ to Time $=18: 24 \mathrm{hrs}$ ).

When the hole was primarily a closed circle (17:00 < Time $<18$ :00, Figures 1 and 2), there was one spectral peak (Figures 3 and 4). As the hole shape evolved toward a semi-circle, the observations are consistent with an increase in the relative amplitude of the quarterwavelength mode for an open semi-circle (Figure 4, where the lower solid curve is the predicted frequency for the lowest-order resonant mode for an open semi-circle given the observed changing diameter and water depth), and with a decrease in the relative amplitude of the sloshing mode for a closed circle (Figure 4). When the hole is a semi-circle (Figures 1d and $2 b$ ), the frequency of the observed spectral peak is consistent with the frequency of the theoretical quarter-wavelength mode (Figure 4, Time=18:48).

The observed spectral peaks do not all fall precisely on the theory curves (Figure 4), partially owing to errors associated with short data records with finite band-width spectral estimates [bars on the symbols in Figure 4 are the width of the frequency band (approximately $0.02 \mathrm{~Hz}$ ) for spectral estimates of 512-s long records with 20 degrees of freedom]. In addition, during the 512-s data records, the hole evolved, with the diameter and depth changing, resulting in a broadening of the resonant frequency peak. However, most of the observed spectral peaks have frequencies that fall within the range of predicted frequencies for $\pm 0.25 \mathrm{~m}$ uncertainties in diameter $(r)$ or length $(L)$ and $\pm 0.05 \mathrm{~m}$ uncertainties in depth $(h)$ (grey shaded areas surrounding each solid theory curve in Figure 4). 
Although the observed spectral peaks for the open semi-circle are consistent with theory $(f \approx$ $0.09 \mathrm{~Hz}$, Figure 4), they also are close to the frequency of the incident waves $(f \approx 0.10 \mathrm{~Hz}$, Figure 3 black curve, Figure 4 dotted line). If the oscillations observed near the open edge of the semi-circle were owing to progressive incident waves, there would be a spectral peak in both cross-shore velocity and sea-surface elevation (or similarly, vertical velocity) fluctuations. In contrast, the observations are consistent with a standing wave at the quarterwavelength resonance frequency $(f=0.09 \mathrm{~Hz})$, with a spectral peak (anti-node) in cross-shore velocity and a spectral trough (node) in sea-surface elevation and vertical velocity (Figure 5). Coherence and phase (not shown) between spatially separated sensors along the cross-shore transect extending $80 \mathrm{~m}$ offshore from the hole are consistent with standing waves at frequencies below about $f=0.06 \mathrm{~Hz}$ (peaks and troughs in cross-shore and vertical velocity fluctuations at $f=0.06 \mathrm{~Hz}$, Figure 5) and progressive waves at higher frequencies (e.g., Figure 9 in Elgar and Guza 1985). Thus, the observations after about Time=18:30, when the hole was an open semi-circle (Figures 1d and 2b) are consistent with a quarter-wavelength standing wave with frequency $f=0.09 \mathrm{~Hz}$ (Figures 4 and 5), and are not an artifact of swash with the incident wave frequency $f=0.10 \mathrm{~Hz}$ entering the hole.

\section{Conclusions}

The water surface and velocities in a 2-m deep, 10-m diameter hole excavated near the lowtide line on an ocean beach oscillated at the frequency $(f=0.14 \mathrm{~Hz})$ of a half-wavelength "sloshing" mode in a circular basin even though the incident waves had frequency $f=0.10 \mathrm{~Hz}$. As the hole diameter decreased owing to sediment influx at the hole edges, the cross-shore sloshing increased in frequency (to $f=0.17 \mathrm{~Hz}$ ) according to theory. About an hour after swash 
started to impact the hole, it began to evolve to a semi-circular shape open on the seaward boundary, and cross-shore velocities fluctuated at a lower frequency $(f=0.09 \mathrm{~Hz})$ associated with a quarter-wavelength resonator, as well as at the closed-circle sloshing frequency. As the semi-circle became more open, the half-wavelength mode decreased in strength and disappeared, while the quarter-wavelength mode increased in strength and in frequency, as predicted by theory.

Acknowledgements: We thank A. Apotsos, L. Goemaat, L. Gorrell, E. Ladouceur, P. Schultz, and the staff of the US Army Corps of Engineers Field Research Facility, Duck NC for helping obtain the field observations. The Office of Naval Research, a National Security Science and Engineering Faculty Fellowship, a National Science Foundation Career award, and a National Defense Science and Engineering Graduate Fellowship provided support. 


\section{References}

Beach, R. and Sternberg, R., Infragravity driven suspended sediment transport in the swash, inner surf, and outer surf zone, Coastal Sediments '91, 114-128, 1991.

Bowen, A. and Inman, D., Edge waves and crescentic bars, J. Geophys. Res. 76, 8662-8671, doi:10.1029/JC076i036p08662, 1971.

Donnely, P. and Macinnis, I., Experiences with self-dredging harbour entrances, Department of Public Works of Canada, Coastal Engineering Volume 11, 1968.

Elgar, S., and Guza, R., Shoaling gravity waves: a comparison between data, linear finite depth theory, and a nonlinear model, J. Fluid Mech. 158, 47-70, 1985.

Evans, O., Classification and origin of beach cusps, J. Geol. 46, 615-627, 1938.

Evans, O., Further observations on the origin of beach cusps, J. Geol. 53, 403-404, 1945.

Gallagher, E., Elgar, S., and Guza, R., Observations of sand bar evolution on a natural beach, J. Geophys. Res. 103, 3203-3215, 1998.

Guza, R. and Inman, D., Edge waves and beach cusps, J. Geophys. Res. 80, 2997-3012, 1975.

James, W., Rectangular resonators for harbor entrances, Proc. Eleventh Conference on Coastal Engineering, ASCE, pp. 1512-1530, 1970a.

James, W., Resolution of partial clapotis, J. Waterways, and Harbors Division, ASCE 96, 165-170, 1970b.

James. W., Spectral response of harbour resonator configurations, Coastal Engineering 111, 2181-2193, 1970c.

James, W., Two innovations for improving harbor resonators, J. Waterways, Harbors, and Coastal Division, ASCE 97, 115-122, 1971 a. 
James, W., Response of rectangular resonators to ocean wave spectra, Proc. Institution of Civil Engineers 48, 51-63, 1971 b.

Korgen, B., Seiches, American Scientist 83, 330-341, 1995.

Lamb, H., Hydrodynamics, 4th Edn. (Cambridge University Press, Cambridge), 708 pp, 1916.

Lane, A., The geology of Nahant, Boston Soc. Nat. Hist., 91-95, 1888.

Lates, M., Recherches hydrauliques de laboratoire sur l' efficacite de quelques types d' ouvrages de protection des petits ports maratimesc contre la penetration des vagues et des alluvions chariees, L' Institut d 'etudes et de Recherches Hydrotechniques, Bucharest, Romania, 1963.

Miles, J., Harbor seiching, Ann. Rev. Fluid Mech. 6, 17-36, 1974.

Miles, J. and Munk, W., Harbor paradox, J. Waterways Harbor Division, ASCE 87, 111-130 1961.

Okihiro, M. and Guza, R., Observations of seiche forcing and amplification in three small harbors, J. Waterways, Port, Coastal, and Ocean Engineering 122, 232-238, 1996.

Prandle, D., Wave resonators for harbour protection, The Dock and Harbour Authority, Volume LV, No. 650, 1974.

Rabinovich, A., Seiches and harbor oscillations, Handbook of Coastal Engineering, ed. Y. Kim (World Scientific Publ., Singapore), 193-236, 2009.

Raichlen, F., Harbor resonance, Estuary and Coastline Hydrodynamics, ed. A. Ippen (McGraw Hill Book Co., New York), pp. 281-340, 1966.

Raichlen, F. and Lee, J., Oscillation of bays, harbors and lakes, Handbook of Coastal and Ocean Engineering, ed. J. Herbich (Gulf Publishing Company Houston, Texas), pp. 1073-1113, 1992. 
Strutt, J.W., The 3rd Baron Rayleigh, The Theory of Sound (Macmillan and Co., London), 326 pp., 1877.

Thornton, E., Humiston, R., Birkemeier, W., Bar trough generation on a natural beach. J. Geophys. Res. 101, 12,097-12,110, 1996.

Unluata, V. and Mei, C., Effect of entrance loss on harbor oscillations, J. Waterways, Harbours, and Coastal Engineering Division ASCE 101, 161-180, 1975.

Valembois, J., Etude de l'action d'ouvrages resonants sur la propagation de la houle, Proc. Minnesota Inst. Hydraulics Conf., Minneapolis, pp: 193-200, 1953.

Watts, G., Field investigation of suspended sediment in the surf zone, Proc. Fourth Conference on Coastal Engineering, ASCE, 181-199, 1953.

Wilson, B., Seiches, Advances in Hydrosciences 8, 1-94, 1972.

Wiegel, R., Tsunamis, storm surges, and harbor oscillations, Oceanographical Engineering, (Prentice-Hall, Englewood Cliffs), Chapter 5, pp: 95-127, 1964.

Wu, J. and Liu, P., Harbor excitations by incident wave groups, J. Fluid Mech. 217, 595-613, 1990. 

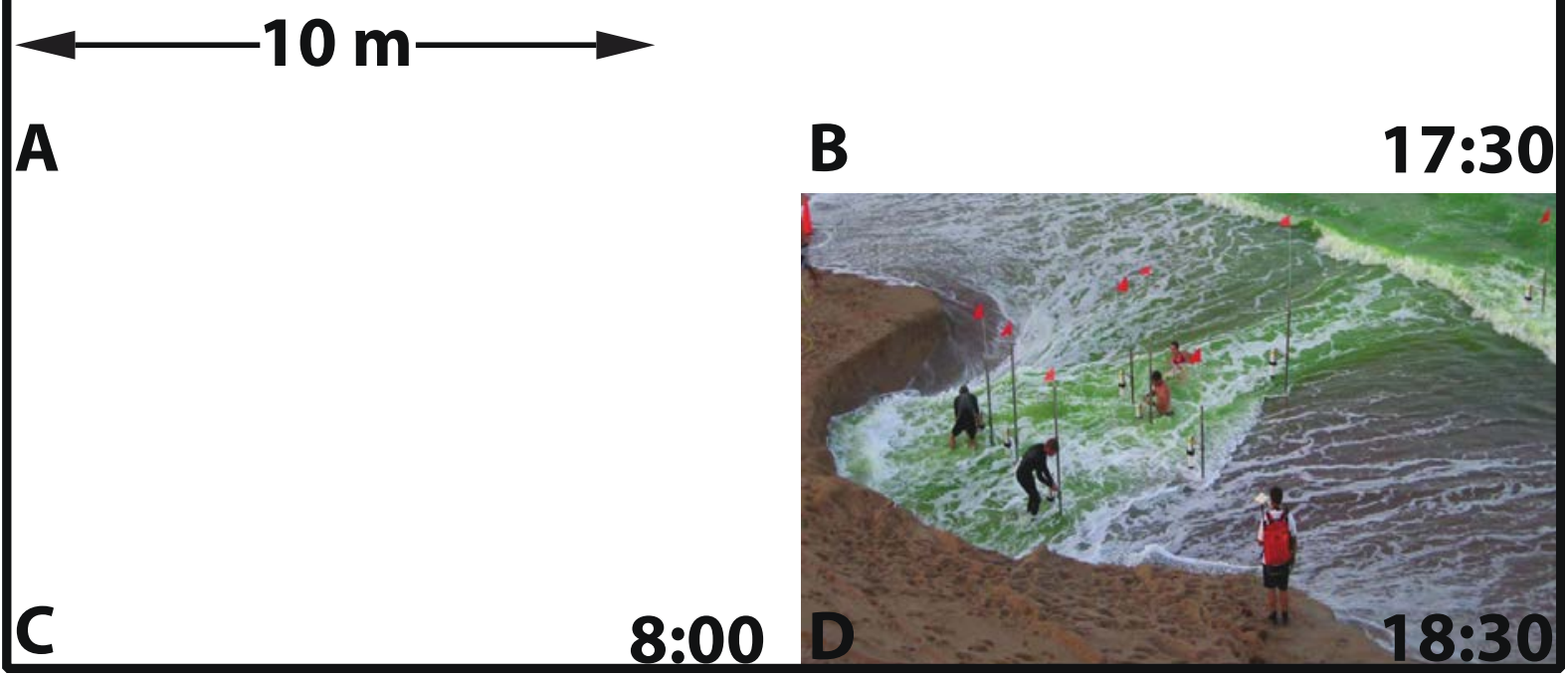

Figure 1. Photographs of the man-made hole at different times (hours (EST) of Sep 19, 2005 are listed). White cylinders on vertical pipes are current meters. 

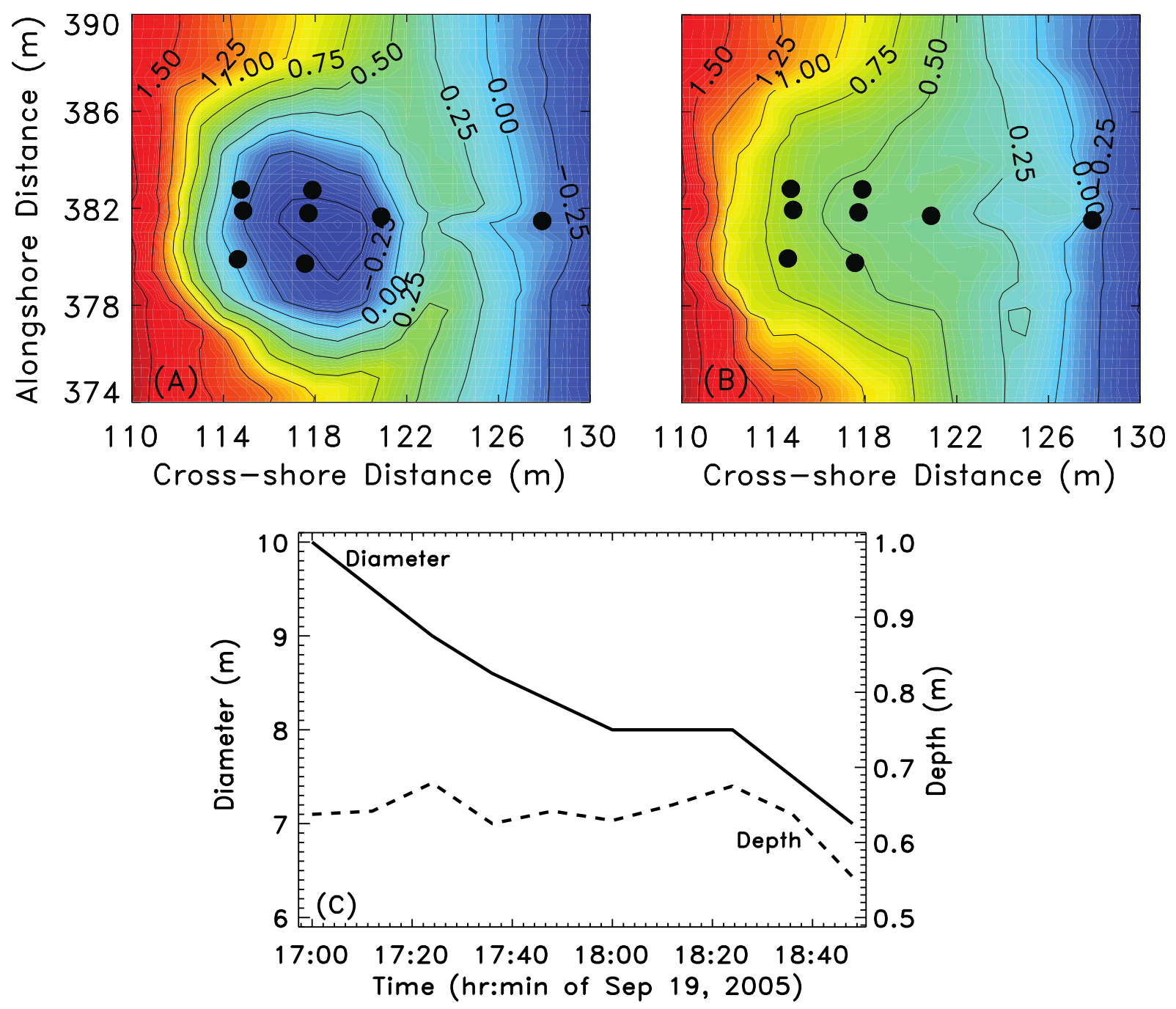

Figure 2. Bathymetry (colors and contours) of the hole at approximately (A) 17:00 and (B) 18:30 hrs as a function of cross- and alongshore distance. Labeled contour lines are drawn every $0.25 \mathrm{~m}$ from about 1.75 (red) to -0.25 (blue) m relative to Mean Sea Level. Symbols are locations of current meters. (C) Diameter of the wetted perimeter (solid curve, left axis) and water depth inside the hole (dashed curve, right axis) versus time. 


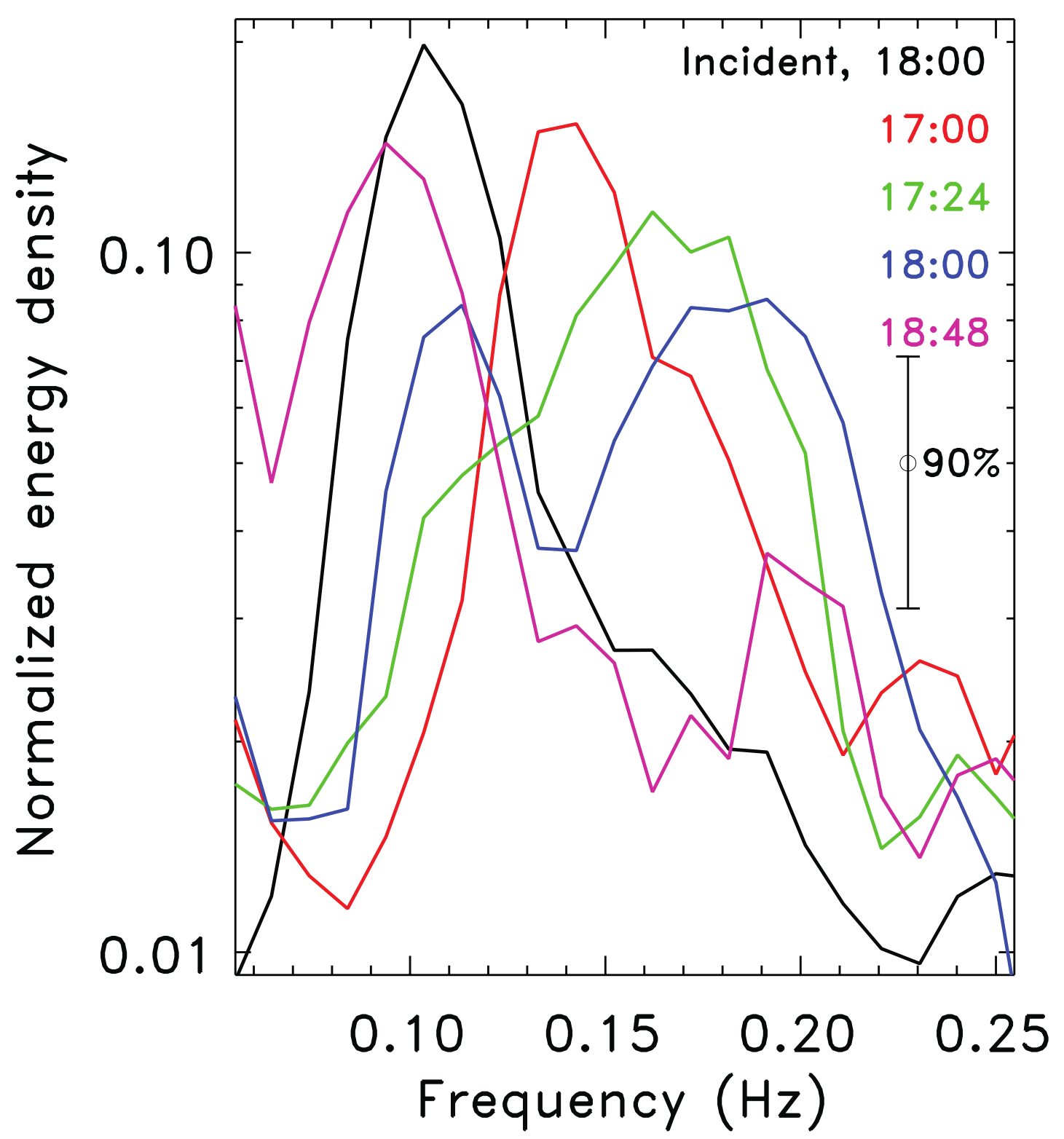

Figure 3: Energy density (normalized by the total variance) of cross-shore velocity observed near the center of the hole (colored curves are different times) and $80 \mathrm{~m}$ offshore (black curve) versus frequency. Times (hour (EST) of Sep. 19, 2005) are listed. 


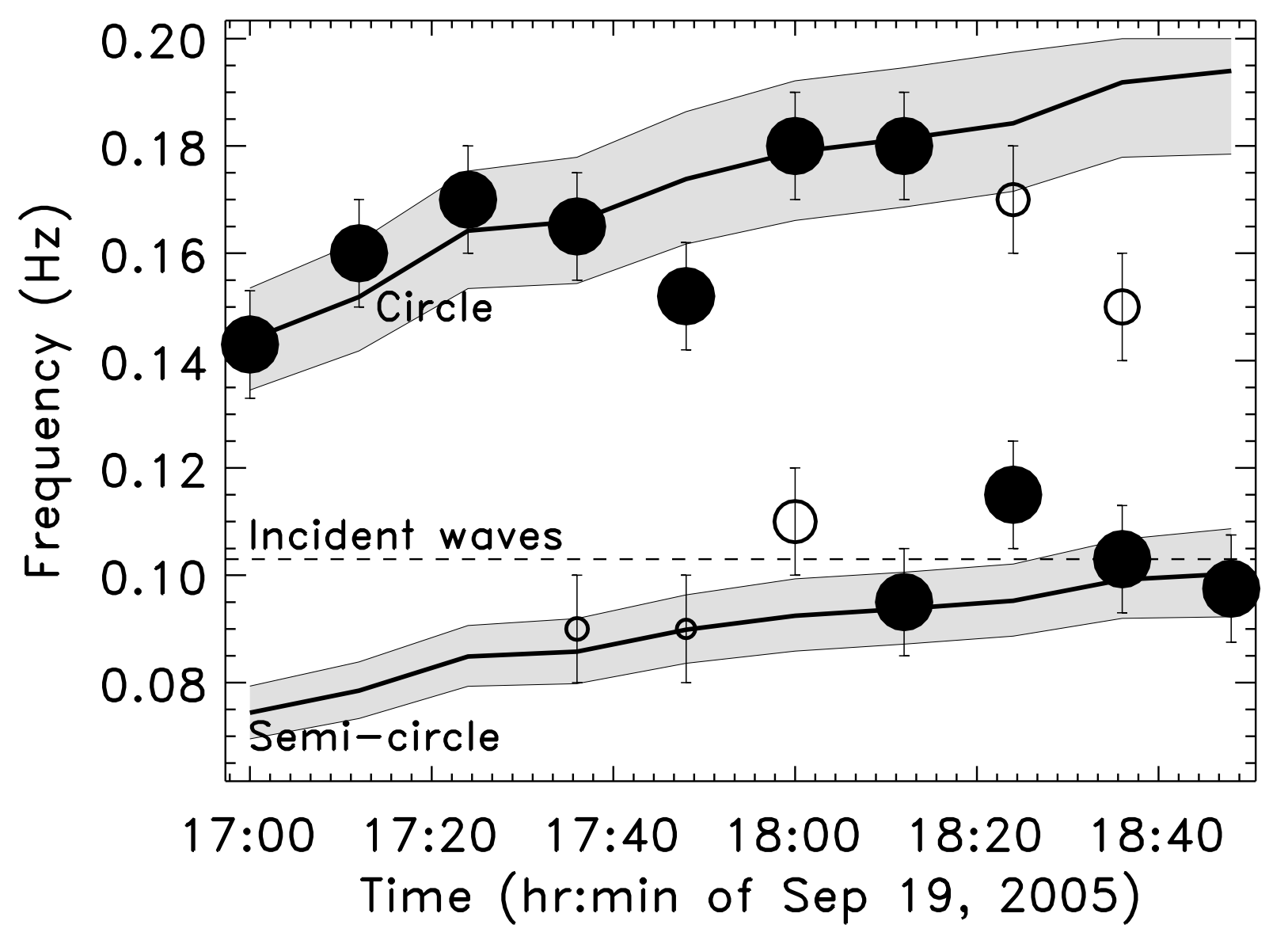

Figure 4: Frequency of observed (symbols) and predicted (solid curves) resonances in crossshore velocity for a closed circular basin and an open semi-circular bay with the observed diameters and depths versus time. Solid circles indicate the frequency of the largest (or the only) spectral peak for that time period, whereas open circles indicate the frequency of a second, smaller spectral peak, with the diameter of the open circle proportional to the area under the smaller peak relative to that under the larger peak. Grey shaded areas encompass predictions for $\pm 0.25 \mathrm{~m}$ uncertainties in diameter and $\pm 0.05 \mathrm{~m}$ uncertainties in depth. 


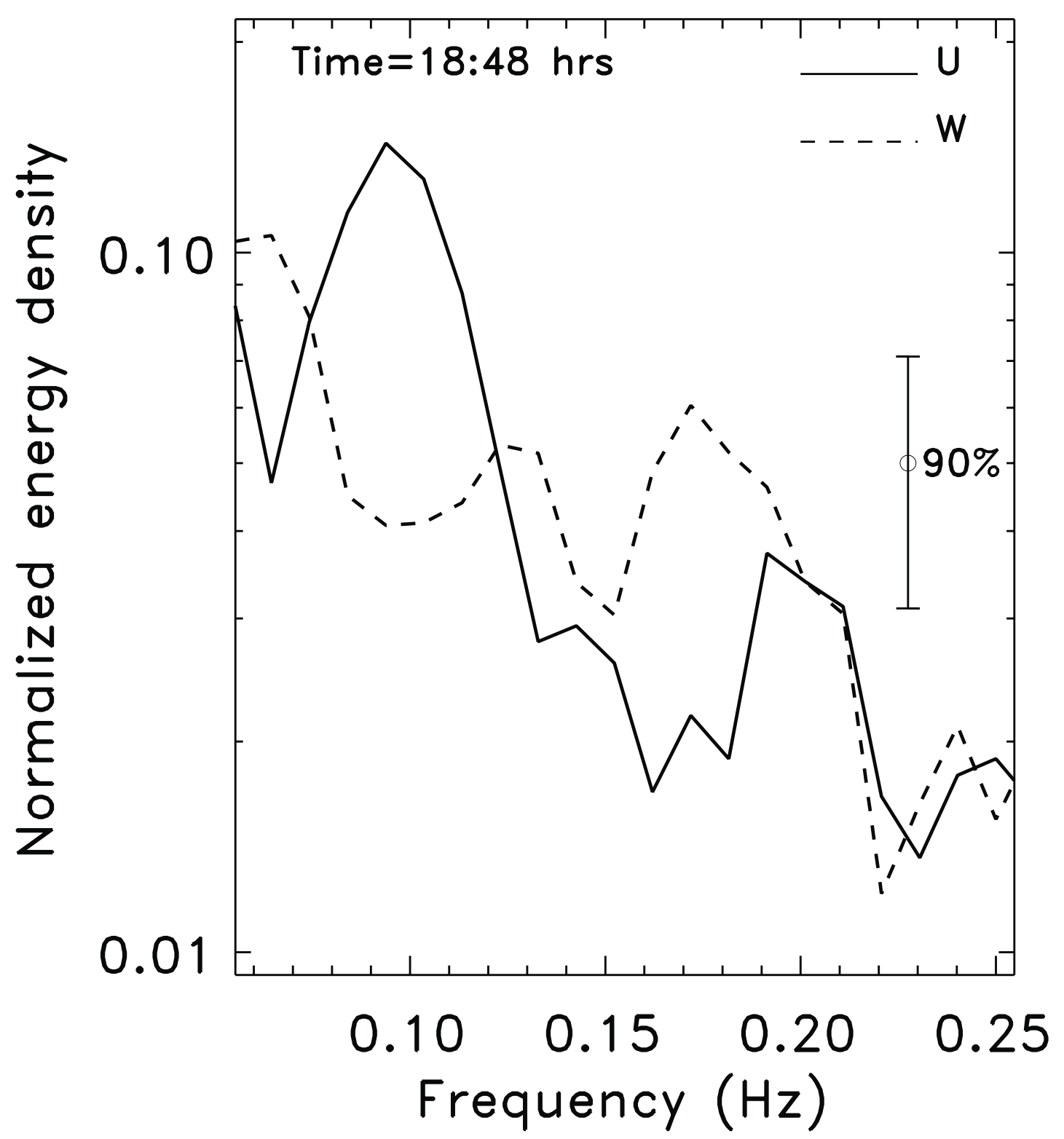

Figure 5: Energy density (normalized by the total variance) of cross-shore (U) and vertical (W) velocity observed at the open boundary of the semi-circular hole versus frequency. 